\title{
Periodontal pathogens and tetracycline resistance genes in subgingival biofilm of periodontally healthy and diseased Dominican adults
}

\author{
James R. Collins ${ }^{1} \cdot$ Alexandre Arredondo $^{2} \cdot$ Alma Roa $^{3} \cdot$ Yleana Valdez $^{3}$. \\ Rubén León ${ }^{2}$. Vanessa Blanc ${ }^{2}$
}

Received: 6 October 2014 / Accepted: 16 June 2015 / Published online: 30 June 2015

(C) The Author(s) 2015. This article is published with open access at Springerlink.com

\begin{abstract}
Objective The objective of this study was to compare the periodontopathogen prevalence and tetracycline resistance genes in Dominican patients with different periodontal conditions. Methods Seventy-seven samples were collected from healthy, gingivitis, chronic $(\mathrm{CP})$ and aggressive $(\mathrm{AgP})$ periodontitis patients. Porphyromonas gingivalis, Treponema denticola, Tannerella forsythia, Aggregatibacter actinomycetemcomitans, Fusobacterium nucleatum, Prevotella intermedia, Parvimonas micra, Eikenella corrodens and Dialister pneumosintes and 11 resistance genes were studied by PCR. P. gingivalis fimA genotype was determined.

Results In healthy patients, $P$. micra and P. intermedia were the most and least frequently detected, respectively. T. forsythia and E. corrodens appeared in $100 \%$ of gingivitis patients. Red complex, D. pneumosintes and E. corrodens were significantly more prevalent in CP compared to healthy patients. F. nucleatum and T. denticola were detected more frequently in AgP. A. actinomycetemcomitans was the most rarely observed in all groups. The fimA II genotype was the
\end{abstract}

Electronic supplementary material The online version of this article (doi:10.1007/s00784-015-1516-2) contains supplementary material, which is available to authorized users.

Vanessa Blanc

blanc@dentaid.es

1 Department of Periodontics, School of Dentistry, Pontificia Universidad Católica Madre y Maestra (PUCMM), Santo Domingo, Dominican Republic

2 Department of Microbiology, Dentaid Research Center, Dentaid S. L., Ronda Can Fatjò 10, Parc Tecnològic del Vallès, 08290 Barcelona, Spain

3 Department of Periodontology, Graduate School, Universidad Católica Santo Domingo, Santo Domingo, Dominican Republic most prevalent in periodontitis patients. Seven tetracyclineresistant genes were detected. $\operatorname{tet}(Q), \operatorname{tet}(32)$ and $\operatorname{tet}(W)$ showed the greatest prevalence. $\operatorname{tet}(32)$ was significantly more prevalent in CP than in healthy patients.

Conclusions Red complex bacteria and D. pneumosintes were significantly the most prevalent species among periodontitis patients. T. forsythia was the most frequently detected in this population. To our knowledge, this is the first study describing the tet(32) gene in subgingival biofilm from healthy and periodontally diseased subjects.

Clinical relevance This study contributes to the knowledge on the subgingival microbiota and its resistance genes of a scarcely studied world region. Knowing the prevalence of resistance genes could impact on their clinical prescription and could raise awareness to the appropriate use of antibiotics.

Keywords Periodontopathogens - Antimicrobial resistance genes · Dominican Republic

\section{Introduction}

Periodontal disease is the result of an imbalance in the microbial ecology of the oral cavity, and it also depends on host susceptibility [1]. The prevalence of this disease is very high in most populations, and gingivitis may affect up to $100 \%$ of the population [2]. Factors such as socio-economic background, gender, smoking, lifestyle or stress appear to have an impact on the prevalence and severity of periodontitis in any given population [3].

Clinical-microbiological studies have shown a close association between periodontitis and the presence of a specific group of microorganisms, mainly Porphyromonas gingivalis, Aggregatibacter actinomycetemcomitans, Treponema denticola and Tannerella forsythia [1,2]. The prevalence of these 
periodontal pathogens has been established in developed countries, and only in recent years has prevalence data of this type been determined in some developing countries [2]. Comparisons of the periodontitis-associated microbiota in different world regions suggest that the distribution of periodontopathogens depends upon geographic location and patient ethnic group [2, 4]. For example, significant differences have been reported for the prevalence of $A$. actinomycetemcomitans in different European populations [5]. Subjects of different ethnic origins living in the USA have also shown different prevalences of this microorganism [6]. This species has also been described to show a high frequency in populations of China and North Africa [7, 8] and a low prevalence in Japan [9], USA [10] and Chile [11]. Moreover, inter- and intra-population clonal variability for different virulence factors has been observed in this microorganism, $[2$, $12,13]$.

Differences in prevalence have also been described for $P$. gingivalis in different ethnic groups [2]. And similarly for this species, genetic variability has been reported in genes related with the synthesis of some virulence factors, for example, the locus responsible for the synthesis of the capsule [14] and the gene responsible for the synthesis of the fimbria ( $\operatorname{fim} A$ ). Six genotypes have been described for the fimA gene, and genotypes II and IV have been associated with periodontitis $[2,15,16]$.

Moreover, an increase in multi-resistant strains in recent years has led to considerable concern throughout the different medical disciplines and has augmented the need to learn about the mechanisms and genes involved in the said process [17, 18]. Relatively little information exists relating to resistance patterns or to the resistance genes that could be present in subgingival microbiota. Recent studies have reported periodontal pathogens resistant to different antibiotics, with percentages that vary according to the populations studied; this could be due to the lack of control over antibiotic use and to poor patient treatment compliance in certain countries $[5,19,20]$. Tetracycline and some of its derivatives have been widely used as adjuvants in the treatment of periodontitis, both topically and systemically [21, 22]. Studies conducted in Europe and the USA report a large presence of resistance genes to this antibiotic in microorganisms from the oral cavity, some of whose frequencies differ, depending on the population studied.

Currently, there is only one study in the Dominican Republic on periodontal microbiota, involving 24 patients [23]. Using culture techniques, a predominance of enteric bacteria and low prevalence and diversity of periodontopathogens were described. Furthermore, in the Dominican Republic, there have been no studies describing the presence of antibiotic resistance genes in subgingival microbiota. In view of the above, the purpose of this study was to describe (i) the prevalence of periodontopathogens, (ii) the fim $A$ gene type present in $P$. gingivalis-positive samples and (iii) the frequency of tetracycline resistance genes in subgingival samples of healthy
Dominican patients and those affected by gingivitis, chronic periodontitis $(\mathrm{CP})$ and aggressive periodontitis $(\mathrm{AgP})$.

\section{Material and methods}

\section{Subject population}

Patients were selected from the Graduate School of Dentistry at the Catholic University of Santo Domingo, Dominican Republic, between 2011 and 2012. Their clinical conditions were defined according to the American Academy of Periodontology's Periodontal Disease Classification Consensus Report [24]. A total of 77 subjects were recruited (Table 1). All subjects signed an institutional review board (IRB)-approved informed consent form. The protocol and study design were previously approved by the university's IRB. Patients with a diagnosis of gingivitis, $\mathrm{CP}$ and $\mathrm{AgP}$ were considered candidates with each individual having at least 12 teeth, not counting third molars. Exclusion criteria included cancer, cardiovascular disease, HIV infection, diabetes, arthritis, pulmonary disease or any other systemic disease. Pregnant women, subjects who had taken antibiotics and/or antiinflammatory drugs within 6 months prior to the study, heavy smokers ( $>10$ cigarettes per day) and patients with a previous periodontal treatment were also excluded.

\section{Clinical procedures}

A complete periodontal examination, excluding third molars, was performed on all subjects. The following clinical parameters were recorded: plaque index (PI), percentage of sites with bleeding on probing (BOP), probing depth (PD) in millimetres and clinical attachment level (CAL) in millimetres. Six sites were examined for each tooth: mesiobuccal, buccal, disto-buccal, disto-lingual, lingual and mesiolingual using a North Carolina periodontal probe. Periodontal patients were described as having a minimum of four sites with a pocket depth $\geq 4 \mathrm{~mm}$ and radiographic evidence of alveolar bone loss.

\section{Subgingival bacterial sampling and processing}

Subgingival samples from $\mathrm{CP}$ and $\mathrm{AgP}$ were taken from the four deepest periodontally affected sites with a probing depth of $\geq 4 \mathrm{~mm}$, one in each quadrant [25]. Sampled sites in healthy and gingivitis patients had a probing depth of $\leq 3 \mathrm{~mm}$, with the deepest sites in each quadrant being selected. After isolating the area with cotton rolls, supragingival deposits were carefully removed with curettes and subgingival microbial samples were obtained by inserting sterile paper points to the bottom of the periodontal pocket and keeping them in place for $20 \mathrm{~s}$. Paper points were pooled in a sterile vial, and samples were 
Table 1 Clinical description of study sample, mean \pm standard deviation

\begin{tabular}{lllll}
\hline & Healthy & Gingivitis & CP & AgP \\
& $N=11$ & $N=10$ & $N=30$ & $3=26$ \\
\hline Age (range) & $28.3 \pm 7.9(24-52)$ & $36.30 \pm 11.50(20-56)$ & $45.7 \pm 10.1(27-65)$ & $33.9 \pm 7.7(18-46)$ \\
Females $(N)$ & 9 & 8 & 17 & 19 \\
Sites with plaque (\%) & $2.2 \pm 0.9$ & $30 \pm 4$ & $54 \pm 19$ & $39 \pm 17$ \\
Probing depth (mm) & $1.5 \pm 0.3$ & $2.5 \pm 0.5$ & $4.4 \pm 1.3$ & $5.9 \pm 2.2$ \\
Probing depth at samples site (mm) & $2.1 \pm 0.4$ & $2.9 \pm 0.2$ & $5.6 \pm 1.1$ & $8.2 \pm 1.5$ \\
CAL (mm) & $0.4 \pm 0.2$ & $2.5 \pm 0.4$ & $5.1 \pm 1.5$ & $6.5 \pm 2.1$ \\
\hline
\end{tabular}

sent to the microbiology laboratory (Dentaid Research Center, Barcelona, Spain) at a controlled temperature of $-20{ }^{\circ} \mathrm{C}$ for processing. Genomic DNA was isolated from subgingival samples using a QIAamp kit (Qiagen, Hilden, Germany) following the manufacturer's instructions. Samples were previously treated with lysozyme $(20 \mathrm{mg} / \mathrm{mL})$ for $7 \mathrm{~min}$ at $37^{\circ} \mathrm{C}$. The DNA concentration was quantified using a Nanodrop ${ }^{\circledR}$ ND-1000 UV-Vis spectrophotometer (Nanodrop Technologies, Wilmington, DE, USA).

\section{Bacterial detection by PCR and fim $A$ gene type identification}

16S rDNA from $P$. gingivalis, $T$. denticola, $T$. forsythia, A. actinomycetemcomitans, P. intermedia and Eikenella corrodens was amplified using specific primers described by Ashimoto et al. [10]. Specific primers for Parvimonas micra (Pm1: 5'-CATgCAAgTCgAACgTgATT-3' and Pm2: 5'CgAAAACCTTCTTCgCTCAC-3') and Fusobacterium nucleatum (Fn1: 5'-TAAAgCgCgTCTAggTggTT-3' and Fn2: 5'-ACggCTTTgCAACTCTCTgT-3') were designed using the NCBI Reference Sequences NR_114338.1 and NR_074412.1, respectively. Possible specific regions for primer design were found through multiple alignments with other oral bacterial sequences (ClustalW2 programme, http://www.ebi.ac.uk). Primers were designed using the primer-Blast programme (http://www.ncbi.nlm.nih.gov/tools/primer-blast/). Specificity was tested by PCR, using total DNA extracted from 15 collection strains as template, where only P. micra DSM 20468 and F. nucleatum DSM 20482 DNA tested positive. The limit of detection was $10^{2} \mathrm{cfu} / \mathrm{ml}$ which was determined using the dilution of pure cultures from both strains.

Dialister pneumosintes primers and PCR conditions were described by Doan et al. [26]. PCR mixes were performed in $25 \mu \mathrm{L}$ containing $100 \mathrm{ng}$ of template, $1 \mathrm{x}$ PCR buffer, $2.5 \mathrm{mM}$ of $\mathrm{MgCl}_{2}, 0.2 \mathrm{mM}$ of each dNTP, $1 \mu \mathrm{M}$ of each primer and $0.5 \mathrm{U}$ Taq Expand DNA polymerase.

The PCR amplification programme was standardised and included initial DNA denaturation at $95{ }^{\circ} \mathrm{C}$ for $5 \mathrm{~min}$ and a total of 35 PCR cycles and each cycle consisting of 1 min of denaturation at $95{ }^{\circ} \mathrm{C}, 1 \mathrm{~min}$ of annealing at $55^{\circ} \mathrm{C}$ and $1 \mathrm{~min}$ of extension at $72^{\circ} \mathrm{C}$. Finally, an extension step was applied at $72{ }^{\circ} \mathrm{C}$ for $10 \mathrm{~min}$. Sterilised Milli-Q water was used as template for negative control in each reaction set, and pure DNA from the following strains was used as positive control reactions: P. gingivalis ATCC 33277, A. actinomycetemcomitans DSM 8324, F. nucleatum DSM 20482, P. intermedia NCTC 13070, T. forsythia ATCC 43037, P. micra DSM 20468, T. denticola ATCC 35405, E. corrodens NCTC 10596 and D. pneumosintes ATCC 33048. PCR reactions were done in duplicate. Amplification results were evaluated by electrophoresis using $4 \%$ agarose gel with ethidium bromide $(0.5 \mathrm{~g} / \mathrm{mL})$ in 1x TAE buffer. The 100 bp DNA Ladder (New England Biolabs, Inc. Ipswich, MA, USA) served as the molecular weight marker. The gels were photographed using a UV light transilluminator GEL DOC ${ }^{\text {TM }}$ XR+ system (Bio-Rad Laboratories Inc. Hercules, CA, USA).

fimA gene type (I, Ib, II, III, IV and V) identification was carried out using specific primers and PCR conditions described by Amano et al. [16] and Nakagawa et al. [27]. The negative control was sterile Milli-Q water.

\section{Detection of tetracycline resistance gene}

The tetracycline resistance genes were detected performing multiplex PCR with 26 primers (Table 2). PCR mixes were performed in $25 \mu \mathrm{L}$ containing $100 \mathrm{ng}$ of template, 1x PCR buffer, $1.0 \mathrm{mM}$ of each dNTP, $0.5 \mu \mathrm{M}$ of each primer and 1.0 U Taq Expand DNA polymerase. The $\mathrm{MgCl}_{2}$ was $2.0 \mathrm{mM}$ for mixes 1 and 2, and $2.5 \mathrm{mM}$ for mixes 3 and 4. The amplification programmes were as follows: 30 PCR cycles of (i) mix 1: $45 \mathrm{~s}$ of denaturation at $95{ }^{\circ} \mathrm{C}, 45 \mathrm{~s}$ of annealing at $64{ }^{\circ} \mathrm{C}$ and $70 \mathrm{~s}$ of extension at $72{ }^{\circ} \mathrm{C}$; (ii) mix 2: $45 \mathrm{~s}$ of denaturation at $95^{\circ} \mathrm{C}, 45 \mathrm{~s}$ of annealing at $60{ }^{\circ} \mathrm{C}$ and $90 \mathrm{~s}$ of extension at $72{ }^{\circ} \mathrm{C}$; (iii) mix 3: $30 \mathrm{~s}$ of denaturation at $95^{\circ} \mathrm{C}, 30 \mathrm{~s}$ of annealing at $58^{\circ} \mathrm{C}$ and $60 \mathrm{~s}$ of extension at $72{ }^{\circ} \mathrm{C}$; and (iv) mix 4: $30 \mathrm{~s}$ of denaturation at $95^{\circ} \mathrm{C}, 30 \mathrm{~s}$ of annealing at $56.5^{\circ} \mathrm{C}$ and $45 \mathrm{~s}$ of extension at $72^{\circ} \mathrm{C}$.

Negative and positive controls were used for each PCR reaction. All reagents used for PCR reactions were purchased from Roche Diagnostics (Penzberg, Germany). Amplification reactions were carried out in a Thermal cycler T3000 (Biometra, Goettingen, Germany). 
Table 2 List of primers for detection of different resistance genes. It also indicates the multiplex group and expected amplicon sizes

\begin{tabular}{|c|c|c|c|c|}
\hline Multiplex group & Primer & Sequence $\left(5^{\prime}-3^{\prime}\right)$ & Product size (bp) & Source \\
\hline \multirow[t]{3}{*}{1} & TetM F & GCG TAC AAG CAC AGA CTC GT & 1142 & This study \\
\hline & $\begin{array}{l}\text { TetM R } \\
\text { TetW F }\end{array}$ & $\begin{array}{l}\text { AGC CAT AGC GTA TCC CCT CC } \\
\text { GAG AGC CTG CTA TAT GCC AGC }\end{array}$ & 168 & {$[28]$} \\
\hline & $\begin{array}{l}\text { TetW R } \\
\text { TetQ F }\end{array}$ & $\begin{array}{l}\text { GGG CGT ATC CAC AAT GTT AAC } \\
\text { AGA ATC TGC TGT TTG CCA GTG }\end{array}$ & 167 & {$[28]$} \\
\hline \multirow{3}{*}{2} & $\begin{array}{l}\text { TetQ R } \\
\text { Tet32 F }\end{array}$ & $\begin{array}{l}\text { CGG AGT GTC AAT GAT ATT GCA } \\
\text { GAA CCA GAT GCT GCT CTT }\end{array}$ & 620 & {$[29]$} \\
\hline & $\begin{array}{l}\text { Tet32 R } \\
\text { TetL F }\end{array}$ & $\begin{array}{l}\text { CAT AGC CAC GCC CAC ATG AT } \\
\text { TCG TTA GCG TGC TGT CAT TC }\end{array}$ & 267 & {$[30]$} \\
\hline & $\begin{array}{l}\text { TetL R } \\
\text { TetS F }\end{array}$ & $\begin{array}{l}\text { GTA TCC CAC CAA TGT AGC CG } \\
\text { GAA AGC TTA CTA TAC AGT AGC }\end{array}$ & 168 & {$[28]$} \\
\hline \multirow{3}{*}{3} & $\begin{array}{l}\text { TetS R } \\
\text { TetO F }\end{array}$ & $\begin{array}{l}\text { AGG AGT ATC TAC AAT ATT TAC } \\
\text { AAC TTA GGC ATT CTG GCT CAC }\end{array}$ & 515 & {$[31]$} \\
\hline & TetO R & TCC CAC TGT TCC ATA TCG TCA & 564 & {$[320]$} \\
\hline & Tet31 R & TGT GCC ATC CCA GTT TGT & & \\
\hline \multirow[t]{4}{*}{4} & TetB F & AAT AGC CAC TAA ATG GGG CG & 243 & This study \\
\hline & $\begin{array}{l}\text { TetB R } \\
\text { TetK F }\end{array}$ & $\begin{array}{l}\text { ATA ACA CCG GTT GCA TTG GT } \\
\text { TCG ATA GGA ACA GCA GTA }\end{array}$ & 169 & {$[30]$} \\
\hline & $\begin{array}{l}\text { TetK R } \\
\text { Tet37 F }\end{array}$ & $\begin{array}{l}\text { CAG CAG ATC CTA CTC CTT } \\
\text { ATG GTT CGC TAT TAC TCT AAC }\end{array}$ & 177 & This study \\
\hline & Tet37 R & ATC AGT CTC ATA TTT CGA CA & & \\
\hline
\end{tabular}

\section{Statistical analysis}

The statistical analysis was performed using SAS System ${ }^{\circledR}$ v9.2 (SAS Institute Inc., Cary, NC, USA). For statistical tests, a nominal significance level of $5 \%(P<0.05)$ was applied. Standard methods were used to calculate descriptive statistics. The association between bacterial detection and clinical parameters was tested using the Mann-Whitney for continuous variables and chi-square or Fisher's exact tests for categorical factors. In order to compare the prevalence of each species, a logistic regression method was performed for each diagnostic group. Multiple comparisons with Tukey adjustment were also performed. To assess whether a population's prevalence of some bacteria was different from the observed value of $100 \%$, the binomial test and Clopper-Pearson confidence limits were calculated. Similarly, the chi-square test and a logistic regression method were performed to assess differences in prevalence of tet genes between the four diagnostic groups.

\section{Results}

Table 1 describes the clinical and demographic characteristics of the study subjects. No statistically significant differences in gender existed between groups. However, significant differences were observed between healthy and periodontitis patients in relation to probing depth $(p<0.001)$ and $\mathrm{CAL}$ $(p<0.001)$ and to the percentage of sites with plaque $(p<0.0001)$. Patients with $\mathrm{AgP}$ showed greater PD $(p<0.0048)$ and CAL $(p<0.04)$ than patients with CP.

Averages of the total bacteria detected for each patient group were as follows: healthy, $2.8 \pm 1.6$; gingivitis, $5.9 \pm 1.3$; CP, $6.9 \pm 1.8$; and $\mathrm{AgP}, 6.7 \pm 1.7$. In addition, the use of the Mann-Whitney-Wilcoxon $U$ test determined that the bacterial average in the healthy subjects was significantly lower than in the other groups, gingivitis $(p=0.0189)$, CP $(p=0.0005)$ and $\operatorname{AgP}(p=0.0011)$. Red complex bacteria and $F$. nucleatum, P. micra and E. corrodens were detected in more than $70 \%$ of the patients studied (in all diagnostic groups). However, the distribution of these species was not the same throughout the four groups (Pearson's chi-square, $p<0.05$ ) (Table 3).

In healthy subjects, the most frequent bacterium was P. micra (63.6\%), although it is worth mentioning that T. forsythia was found in over $50 \%$ of the healthy population. Furthermore, P. intermedia was not found in this group.

$P$. gingivalis, $T$. denticola and $T$. forsythia were the most prevalent in periodontally diseased patients. $P$. gingivalis and T. denticola were significantly more prevalent in diseased patients compared to healthy patients. The detection frequency of $T$. denticola in the healthy patient group was significantly lower than in the $\mathrm{CP}$ and $\mathrm{AgP}$ patient groups, with $p$ values of 0.0045 and 0.0048 , respectively. And the same is observed when studying the percentages of $D$. pneumosintes, as this species was found mainly in patients with aggressive 
Table 3 Number and percentage of positive subjects for each microorganism in the four studied groups

\begin{tabular}{|c|c|c|c|c|c|c|c|c|c|c|}
\hline \multirow[t]{2}{*}{ Bacteria } & \multicolumn{2}{|c|}{ Healthy $(n=11)$} & \multicolumn{2}{|c|}{ Gingivitis $(n=10)$} & \multicolumn{2}{|c|}{$\mathrm{CP}(n=30)$} & \multicolumn{2}{|c|}{$\operatorname{AgP}(n=26)$} & \multicolumn{2}{|c|}{ Total $(n=77)$} \\
\hline & $N^{\mathrm{a}}$ & $\%$ & $N^{\mathrm{a}}$ & $\%$ & $N^{\mathrm{a}}$ & $\%$ & $N^{\mathrm{a}}$ & $\%$ & $N^{\mathrm{a}}$ & $\% \mathrm{~b}$ \\
\hline P. gingivalis & 2 & 18.2 & 7 & 70 & 28 & $93.3^{*}$ & 23 & $88.5^{*}$ & 60 & 77.9 \\
\hline T. denticola & 3 & 27.3 & 9 & 90 & 27 & $90^{*}$ & 24 & $92.3^{*}$ & 63 & 81.8 \\
\hline T. forsythia & 6 & 54.5 & 10 & 100 & 29 & $96.7^{*}$ & 24 & 92.3 & 69 & 89.6 \\
\hline A. actinomycetemcomitans & 2 & 18.2 & 1 & 10 & 10 & 33.3 & 6 & 23.1 & 19 & 24.7 \\
\hline P. intermedia & 0 & 0 & 2 & 20 & 16 & 53.3 & 7 & 26.9 & 25 & 32.5 \\
\hline F. nucleatum & 5 & 45.4 & 9 & 90 & 24 & 80 & 24 & $92.3^{*}$ & 62 & 80.5 \\
\hline P. micra & 7 & 63.6 & 8 & 80 & 27 & 90 & 23 & 88.5 & 65 & 84.4 \\
\hline D. pneumosintes & 1 & 9.1 & 3 & 30 & 20 & $66.7^{*}$ & 22 & $84.6^{*}$ & 46 & 59.7 \\
\hline E. corrodens & 5 & 45.4 & 10 & 100 & 27 & $90^{*}$ & 21 & 80.8 & 63 & 81.8 \\
\hline Mean bacteria in each group of patients $( \pm \mathrm{SD})$ & \multicolumn{2}{|c|}{$2.8 \pm 1.6$} & \multicolumn{2}{|c|}{$5.9 \pm 1.3$} & \multicolumn{2}{|c|}{$6.9 \pm 1.8$} & \multicolumn{2}{|c|}{$6.7 \pm 1.7$} & & \\
\hline
\end{tabular}

${ }^{\mathrm{a}} N$ number of positive subjects for each bacterium

$\mathrm{b} \%$ percentage of positive subjects for each bacterium

* $P$ values $<0.05$ obtained from statistical comparison between the prevalence data of healthy and diseased subjects

$(84.6 \%)$ and chronic periodontitis $(66.7 \%)$. T. forsythia was frequently detected in all groups studied, although it was significantly more prevalent in patients with chronic periodontitis than in healthy patients. Moreover, the Clopper-Pearson test showed statistical differences between the gingivitis group and the healthy groups for this species. E. corrodens behaved similarly to $T$. forsythia (Table 3).

F. nucleatum, T. forsythia and T. denticola had over $92 \%$ occurrence in AgP and were the most prevalent species in this group. Of these three species, F. nucleatum and T. denticola were much more frequently detected in these patients than in healthy subjects. However, A. actinomycetemcomitans was the least prevalent species in all patient groups, and no significant differences were observed for this species between the healthy and diseased subjects. This bacterium was only present in $24.7 \%$ of the entire test population (Table 3 ).

Of the total patients included in the study, $77.9 \%(n=60)$ tested positive for $P$. gingivalis. In 57 of these, the fim $A$ gene variant was determined. The III, V and Ib genotypes were not detected in any of the patients. By using Pearson's chi-squared test, it was determined that $\operatorname{fim} A$ I, II and IV genotypes were not equally distributed across the four groups ( $p=0.0003)$. The genotype II frequency was significantly higher in AgP $(84 \%)$ and CP (75.8\%) patients.

The presence of 11 tetracycline resistance genes was analysed. tet $(S)$, tet $(31)$, tet $(37)$ and $\operatorname{tet}(K)$ genes were not detected. $\operatorname{tet}(L)$ and $\operatorname{tet}(B)$ were only detected in one CP patient. This set of six genes was excluded from subsequent statistical analysis. The weighted average number of genes per patient showed that in healthy subjects the value (1.47) was one point lower than that obtained in patients with chronic periodontitis (2.88) (Table 4). Lastly, we observed that the most frequently detected gene in this population was $\operatorname{tet}(Q)$, which was present in 54 of the 75 patients tested. And when comparing resistance gene prevalence in the different patient groups, significant differences were found for the $\operatorname{tet}(Q)$ and $\operatorname{tet}(32)$ genes. We observed that these genes were much more prevalent in CP than in the healthy patient group ( $p=0.023$ and $p=0.019$, respectively).

\section{Discussion}

In this cross-sectional study, we used PCR to determine the prevalence of nine periodontopathogens in the subgingival microbiota of 77 Dominican patients diagnosed as healthy,

Table 4 Prevalence of antibiotic resistance genes in subgingival samples from the different periodontal conditions

\begin{tabular}{|c|c|c|c|c|c|c|c|c|}
\hline \multirow[t]{2}{*}{ Gene } & \multicolumn{2}{|c|}{ Healthy } & \multicolumn{2}{|c|}{ Gingivitis } & \multicolumn{2}{|l|}{$\mathrm{CP}$} & \multicolumn{2}{|l|}{$\mathrm{AgP}$} \\
\hline & $\mathrm{P} / \mathrm{A}$ & $\%$ & $\mathrm{P} / \mathrm{A}$ & $\%$ & $\mathrm{P} / \mathrm{A}$ & $\%$ & $\mathrm{P} / \mathrm{A}$ & $\%$ \\
\hline $\operatorname{tet}(31)$ & $0 / 11$ & - & $0 / 9$ & - & $0 / 29$ & - & $0 / 26$ & - \\
\hline $\operatorname{tet}(32)$ & $1 / 11$ & 9.09 & $6 / 9$ & 66.7 & $21 / 29$ & 72.4 & $16 / 26$ & 61.5 \\
\hline $\operatorname{tet}(37)$ & $0 / 11$ & - & $0 / 9$ & - & $0 / 29$ & - & $0 / 26$ & - \\
\hline $\operatorname{tet}(B)$ & $0 / 11$ & - & $0 / 9$ & - & $1 / 17$ & 5.88 & $0 / 26$ & - \\
\hline $\operatorname{tet}(K)$ & $0 / 11$ & - & $0 / 9$ & - & $0 / 29$ & - & $0 / 26$ & - \\
\hline $\operatorname{tet}(L)$ & $0 / 11$ & - & $0 / 9$ & - & $1 / 29$ & 3.45 & $0 / 26$ & - \\
\hline $\operatorname{tet}(M)$ & $5 / 11$ & 45.5 & $1 / 9$ & 11.1 & $9 / 29$ & 31.0 & $7 / 26$ & 26.9 \\
\hline $\operatorname{tet}(O)$ & $1 / 9$ & 11.1 & $2 / 6$ & 33.3 & $9 / 29$ & 31.0 & $2 / 23$ & 8.70 \\
\hline $\operatorname{tet}(Q)$ & $5 / 11$ & 45.5 & $6 / 9$ & 66.7 & $24 / 29$ & 82.8 & $19 / 26$ & 73.1 \\
\hline $\operatorname{tet}(S)$ & $0 / 11$ & - & $0 / 9$ & - & $0 / 29$ & - & $0 / 26$ & - \\
\hline $\operatorname{tet}(W)$ & $4 / 11$ & 36.4 & $2 / 9$ & 22.2 & $18 / 29$ & 62.1 & $17 / 26$ & 65.4 \\
\hline WAN genes/patient & $1 / 48$ & & 2.0 & & 2.89 & & 2.36 & \\
\hline
\end{tabular}

Due to a lack of samples, not all the patients could not be analysed $W A N$ weighted average number of genes per patient, $P / A$ positive/all 
gingivitis, $\mathrm{CP}$ and $\mathrm{AgP}$. The fimA genotypes were determined in $P$. gingivalis-positive patients. Finally, the frequency of 11 tetracycline resistance genes was also analysed.

Little information is available regarding subgingival microbiota in Central America and the Caribbean countries. In the Dominican Republic, only one work exists, in which by using culturing methods, the subgingival microbiota of 24 patients with advanced periodontitis were studied. In the said study, a high rate of enteric bacteria was found and the only member of the red complex detected was $P$. gingivalis. A low prevalence of spirochetes was also observed [23]. Our study, using PCR, showed an incidence of red complex microorganisms of around $90 \%$ in periodontitis patients. The high prevalence of $P$. gingivalis in the $\mathrm{CP}$ group was similar to that obtained in other studies performed in Colombia [33], Chile [11] and Spain [34]. Although in our case, no significant differences were found between the $\mathrm{CP}$ and $\mathrm{AgP}$ patient groups.

In subjects with $\mathrm{CP}, T$. forsythia was the most frequently detected species $(96.7 \%$ ), which differs from that which is described in other Latin American countries (Chile [16.2 \%] and Colombia [39\%]) [34] and in European countries, including the Netherlands (73.3 \%) [5], UK (44.4 \%) [35] and Spain (36.1\%) [34]. A high incidence of T. forsythia was also observed in the healthy (54.5\%) and gingivitis (100\%) groups. In Thai urban adults, Torrungruang et al. [36] observed a high prevalence of $T$. forsythia in healthy and CP patients, and they were not able to associate this microorganism with this disease. Further studies may be necessary to establish clear associations between T. forsythia and periodontitis in the Dominican population. It is likely that the use of PCR in our study allowed us to observe this species more frequently compared to other studies that only employed culture techniques [37, 38].

D. pneumosintes is a species that is frequently found in deep sites and in severe forms of the disease [26, 39], a fact that coincides with our study, as it was detected more frequently in patients with periodontitis compared to healthy or gingivitis patients. Even so, the high colonisation of this species in the Dominican Republic contrasts with that described by Botero et al. in Colombia [33] and is similar to that found in Brazil [39]. That being said, some studies report a frequency for this species of greater than $70 \%$ in healthy patients [40].

The literature indicates that there are differences between the subgingival microbiota of the $\mathrm{CP}$ and AgP groups [24], and further emphasises the strong association between the presence of A. actinomycetemcomitans and AgP [41, 42]. In our study, no significant differences were observed between the species studied in the $\mathrm{CP}$ and AgP groups. Even A. actinomycetemcomitans was less frequently detected in AgP than in CP. The frequency of this species in the Dominican Republic was similar to that reported in Chile (19.4\%) [11] and higher than that described in Colombia (8.3\%) [33]. High prevalence of this bacterium has been reported for $\mathrm{AgP}$ in other populations: $60.4 \%$ in Morocco [8], $62 \%$ in China [7], $75 \%$ in Korea [43], $80 \%$ in Brazil [44] and $84.3 \%$ in Taiwan [45]. This may be due to ethnic differences between populations $[2,3]$.

Some studies conducted in Brazil have found a high frequency of the JP2 clone of A. actinomycetemcomitans [46, 47]; this overproducer of leukotoxin has been closely associated in some populations with $\mathrm{AgP}$ [48]. In our study, we attempted to determine the presence of this clone, although the sample amount only allowed for testing four A. actinomycetemcomitans-positive samples (data not shown). Nevertheless, we were able to observe the genetic variability of the fimA gene of $P$. gingivalis. Fifty-seven of the 60 $P$. gingivalis-positive samples were studied, and fim $A$ type II was the most frequently found allele in periodontitis patients (75.9\% [CP]; $84 \%[\mathrm{AgP}])$. This is in agreement with other studies where genotypes II and IV are more frequently detected in periodontitis patients than in healthy ones [2, 16, 49].

The oral cavity has been described as a reservoir of potentially transferable antibiotic resistance genes [50]. In the Dominican Republic, there are no policies controlling the sale of antibiotics, and the livestock industry is authorised to use subtherapeutic levels of antibiotic as growth promoters in poultry feed [51]. This can result in the emergence of resistant or multi-resistant bacterial strains [52]. Tetracyclines have been used as a therapy for periodontitis as a monotherapy or as an adjunct to scaling and root planing with different degrees of efficacy [22]. Although nowadays it is not used regularly, some of its derivatives are used in subantimicrobial doses for the downregulation of metalloproteinase activity [53]. Studies have been carried out in Europe and the USA to analyse the subgingival presence of these resistance genes in healthy and periodontally diseased subjects [50]. In our study, we have tested for genes encoding efflux pumps: tet(31), tet($K)$, $\operatorname{tet}(L)$, ribosomal protection proteins (RPP): $\operatorname{tet}(B), \operatorname{tet}(M)$, $\operatorname{tet}(O), \operatorname{tet}(Q), \operatorname{tet}(S), \operatorname{tet}(W)$ and $\operatorname{tet}(32)$ and enzymatic inactivation tet(37). This covers the different resistance mechanisms described for this antibiotic. Several of these genes have been detected in bacteria from the oral cavity, while for other genes no references exist in the literature in relation to the oral environment $[50,54]$. In our study, the most prevalent gene in periodontitis was $\operatorname{tet}(Q)$ while $\operatorname{tet}(M)$ showed a low prevalence. However, studies by Ioannidis et al. [55] and Kim et al. [56] reported both genes as the most frequent in diseased patients in Europe and the USA, respectively. In Dominican patients, tet(32) was the second most frequently detected gene in periodontitis; it is worth noting that, to our knowledge, this is the first study to report the presence of this gene in the subgingival biofilm of healthy and periodontally diseased patients.

The results of this study show a high prevalence of red complex organisms in patients with $\mathrm{CP}$ and $\mathrm{AgP}$. However, the high incidence of $T$. forsythia in healthy and gingivitis 
patients may suggest further study is needed to determine the role of this species in the Dominican population.

Unfortunately, a larger number of patients was not possible for this study. Even so, and considering the existing knowledge on subgingival microbiota and the presence and distribution of antibiotic resistance genes in the Dominican Republic and Central America, we believe that this study provides interesting data in relation to the subgingival microbiota of this population, as some differences were found compared to other studies performed in populations in America and Europe.

Moreover, we found a wide variety of tetracycline resistance genes with prevalences differing from those described in European and North American populations. Considering the current public health concern surrounding the presence of multi-resistant bacteria caused by the use and abuse of antibiotics [18], it would be wise to conduct broader studies, allowing us to map the diversity, distribution and dissemination of resistance genes in different countries in America.

Acknowledgments The authors want to express their gratitude to all the participants of the study. The English translation of this article is by Mrs. Ann Bangle and Mr. Graham Stewart.

Funding No external funding, apart from the support of the authors' institution, was available for this study.

Conflict of interest The authors declare that they have no competing interests.

Ethical approval The study protocol was reviewed and approved by the Institutional Review Board of the Catholic University of Santo Domingo.

Open Access This article is distributed under the terms of the Creative Commons Attribution 4.0 International License (http:// creativecommons.org/licenses/by/4.0/), which permits unrestricted use, distribution, and reproduction in any medium, provided you give appropriate credit to the original author(s) and the source, provide a link to the Creative Commons license, and indicate if changes were made.

\section{References}

1. Socransky SS (2000) Haffajee AD (2005) Periodontal microbial ecology. Periodontol 38:135-187

2. Rylev M, Kilian M (2008) Prevalence and distribution of principal periodontal pathogens worldwide. J Clin Periodontol 35:346-361

3. Genco RJ (2000) Borgnakke WS (2013) Risk factors for periodontal disease. Periodontol 62:59-94

4. Haffajee AD, Bogren A, Hasturk H, Feres M, López NJ, Socransky SS (2004) Subgingival microbiota of chronic periodontitis subjects from different geographic locations. J Clin Periodontol 31:9961002

5. Sanz M, van Winkelhoff AJ, Herrera D, Dellemijn-Kippuw N, Simón R, Winkel E (2000) Differences in the composition of the subgingival microbiota of two periodontitis populations of different geographical origin. A comparison between Spain and The Netherlands. Eur J Oral Sci 108:383-392

6. Umeda M, Chen C, Bakker I, Contreras A, Morrison JL, Slots J (1998) Risk indicators for harbouring periodontal pathogens. J Periodontol 69:1111-1118

7. Mombelli A, Gmür R, Frey J, Meyer J, Zee KY, Tam JO, et al (1998) Actinobacillus actinomycetemcomitans and Porphyromonas gingivalis in young Chinese adults. Oral Microbiol Immunol 13:231-237

8. Haubek D, Ennibi OK, Poulsen K, Poulsen S, Benzarti N, Kilian M (2001) Early-onset periodontitis in Morocco is associated with the highly leukotoxic clone of Actinobacillus actinomycetemcomitans. J Dent Res 80:1580-1583

9. Tomita S, Komiya-Ito A, Imamura K, Kita D, Ota K, Takamayama S, et al (2013) Prevalence of Aggregatibacter actinomycetemcomitans, Porphyromonas gingivalis and Tannerella forsythia in Japanese patients with generalized chronic and aggressive periodontitis. Microb Pathog 61-62:11-15

10. Ashimoto A, Chen C, Bakker I, Slots J (1996) Polymerase chain reaction detection of 8 putative periodontal pathogens in subgingival plaque of gingivitis and advanced periodontitis lesions. Oral Microbiol Immunol 11:266-273

11. Gajardo M, Silva N, Gómez L, León R, Parra B, Contreras A, et al (2005) Prevalence of periodontopathic bacteria in aggressive periodontitis patients in a Chilean population. J Periodontol 76:289294

12. Yang HW, Asikainen S, Doğan B, Suda R, Lai CH (2004) Relationship of Actinobacillus actinomycetemcomitans serotype $\mathrm{b}$ to aggressive periodontitis: frequency in pure cultured isolates. $\mathrm{J}$ Periodontol 75:592-599

13. Haubek D, Poulsen K, Kilian M (2007) Microevolution and patterns of dissemination of the JP2 clone of Aggregatibacter (Actinobacillus) actinomycetemcomitans. Infect Immun 75:30803088

14. Aduse-Opoku J, Slaney JM, Hashim A, Gallagher A, Gallagher RP, Rangarajan M, Boutaga K, Laine ML, Van Winkelhoff AJ, Curtis MA (2006) Identification and characterization of the capsular polysaccharide (K-antigen) locus of Porphyromonas gingivalis. Infect Immun 74:449-460

15. Kuboniwa M, Inaba H (2000) Amano A (2010) Genotyping to distinguish microbial pathogenicity in periodontitis. Periodontol 54:136-159

16. Amano A, Kubinowa M, Nakagawa I, Akiyama S, Morisaki I, Hamada S (2000) Prevalence of specific genotypes of Porphyromonas gingivalis fimA and periodontal health status. J Dent Res 79:1664-1668

17. Gilbert P, McBain AJ (2003) Potential impact of increased use of biocides in consumer products on prevalence of antibiotic resistance. Clin Microbiol Rev 16:189-208

18. Bush K, Courvalin P, Dantas G, Davies J, Eisenstein B, Huovinen P, et al (2011) Tackling antibiotic resistance. Nat Rev Microbiol 9: 894-896

19. Ardila CM, Granada MI, Guzmán IC (2010) Antibiotic resistance of subgingival species in chronic periodontitis patients. J Periodontal Res 45:557-563

20. Veloo AC, Seme K, Raangs E, Rureunga P, Singadji W-MG, et al (2012) Antibiotic susceptibility profiles of oral pathogens. Int J Antimicrob Agents 40:450-454

21. Chopra I, Roberts M (2001) Tetracycline antibiotics: mode of action, applications, molecular biology, and epidemiology of bacterial resistance. Microbiol Mol Biol Rev 65:232-260

22. Herrera D, Alonso B, León R, Roldán S, Sanz M (2008) Antimicrobial therapy in periodontitis: the use of systemic antimicrobials against the subgingival biofilm. J Clin Periodontol 35:4566 
23. Slots J, Rams TE, Feik D, Taveras HD, Gillespie GM (1991) Subgingival microflora of advanced periodontitis in the Dominican Republic. J Periodontol 62:543-547

24. Armitage GC (1999) Development of a classification system for periodontal diseases and conditions. Ann Periodontol 4:1-6

25. Mombelli A, McNabb H, Lang NP (1991) Black-pigmenting Gram-negative bacteria in periodontal disease. II. Screening strategies for detection of $P$. gingivalis. J Periodontal Res $26: 308-313$

26. Doan N, Contreras A, Flynn J, Slots J, Chen C (2000) Molecular identification of Dialister pneumosintes in subgingival plaque of humans. J Clin Microbiol 38:3043-3047

27. Nakagawa I, Amano A, Ohara-Nemoto Y, Endoh N, Morisali I, Kimura S, et al (2002) Identification of a new variant of fimA gene of Porphyromonas gingivalis and its distribution in adults and disabled populations with periodontitis. J Periodontal Res 37:425-432

28. Aminov RI, Garrigues-Jeanjean N, Mackie RI (2001) Molecular ecology of tetracycline resistance: development and validation of primers for detection of tetracycline resistance genes encoding ribosomal protection proteins. Appl Environ Microbiol 67:22-32

29. Warburton P, Roberts AP, Allan E, Seville L, Lancaster H, Mullany P (2009) Characterization of tet(32) genes from the oral metagenome. Antimicrob Agents Chemother 53:273-276

30. Ng LK, Martin I, Alfa M, Mulvey M (2001) Multiplex PCR for the detection of tetracycline resistant genes. Mol Cell Probes 15:209215

31. Manch-Citron JN, López GH, Dey A, Rapley JW, MacNeill SR, Cobb CM (2000) PCR monitoring for tetracycline resistance genes in subgingival plaque following site-specific periodontal therapy. A preliminary report. J Clin Periodontol 27:437-446

32. Bojesen AM, Bager RJ, Ifrah D, Aarestrup FM (2011) The rarely reported tet(31) tetracycline resistance determinant is common in Gallibacterium anatis. Vet Microbiol 149:497-499

33. Botero JE, Contreras A, Lafaurie G, Jaramillo A, Betancourt M, Arce RM (2007) Occurrence of periodontopathic and superinfecting bacteria in chronic and aggressive periodontitis subjects in a Colombian population. J Periodontol 78:696-704

34. Herrera D, Contreras A, Gamonal J, Oteo A, Jaramillo A, Silva N, et al (2008) Subgingival microbial profiles in chronic periodontitis patients from Chile, Colombia and Spain. J Clin Periodontol 35: $106-113$

35. Ledder RG, Gilbert P, Huws SA, Aarons L, Ashley MP, Hull PS, McBain AJ (2007) Molecular analysis of the subgingival microbiota in health and disease. Appl Environ Microbiol 73:516-523

36. Torrungruang K, Bandhaya P, Likittanasombat K, Grittayaphong C (2009) Relationship between the presence of certain bacterial pathogens and periodontal status of urban Thai adults. J Periodontol 80: 122-129

37. Riggio MP, Macfarlane TW, Mackenzie D, Lennon A, Smith AJ, Kinane D (1996) Comparison of polymerase chain reaction and culture methods for detection of Actinobacillus actinomycetemcomitans and Porphyromonas gingivalis in subgingival plaque samples. J Periodontal Res 31:496-501

38. Ali RW, Johannessen AC, Dahlén G, Socransky SS, Skaug N (1997) Comparison of the subgingival microbiota of periodontally healthy and diseased adults in northern Cameroon. J Clin Periodontol 24:830-835

39. Ferraro CT, Gornic C, Barbosa AS, Peixoto RJ, Colombo AP (2007) Detection of Dialister pneumosintes in the subgingival biofilm of subjects with periodontal disease. Anaerobe 13:244-248
40. Nonnenmacher C, Dalpke A, Rochon J, Flores-de-Jacoby L, Mutters R, Heeg K (2005) Real-time polymerase chain reaction for detection and quantification of bacteria in periodontal patients. J Periodontol 76:1542-1549

41. Zambon JJ (1985) Actinobacillus actinomycetemcomitans in human periodontal disease. J Clin Periodontol 12:1-20

42. Fine DH, Kaplan JB, Kachlany SC (2000) Schreiner HC (2006) How we got attached to Actinobacillus actinomycetemcomitans: a model for infectious diseases. Periodontol 42:114-157

43. Lee JW, Choi BK, Yoo YJ, Choi SH, Cho KS, Chai JK, et al (2003) Distribution of periodontal pathogens in Korean aggressive periodontitis. J Periodontol 74:1329-1335

44. Tinoco EM, Beldi MI, Loureiro CA (1997) Localized juvenile periodontitis and Actinobacillus actinomycetemcomitans in a Brazilian population. Eur J Oral Sci 105:9-14

45. Yang HW, Huang YF, Chan Y, Chou MY (2005) Relationship of Actinobacillus actinomycetemcomitans serotypes to periodontal condition: prevalence and proportions in subgingival plaque. Eur J Oral Sci 113:28-33

46. Guazeli-Amin VH, Avila-Campos MJ, Barbosa DS, Gaetti-Jardim Jr E, Trevisan Jr W, Itano EN (2000) Leukotoxic activity of Actinobacillus actinomycetemcomitans isolated from Brazilian periodontal patients. Anaerobe 6:341-346

47. Gaetti-Jardim Jr E, Wahasugui TC, Tomazinho PH, Marques MM, Nakano V, Avila-Campos MJ (2008) Distribution of biotypes and leukotoxic activity of Aggregatibacter actinomycetemcomitans isolated from Brazilian patients with chronic periodontitis. Braz J Microbiol 39:658-663

48. Haubek D, Johansson A (2014) Pathogenicity of the highly leukotoxic JP2 clone of Aggregatibacter actinomycetemcomitans and its geographic dissemination and role in aggressive periodontitis. J Oral Microbiol 14:6. doi:10.3402/jom.v6.23980

49. Missailidis CG, Emeda JE, Ota-Tsuzuki C, Anzai D, Mayer MPA (2004) Distribution of fimA genotypes of Porphyromonas gingivalis in subjects with various periodontal conditions. Oral Microbiol Immunol 19:224-229

50. Roberts AP, Mullany P (2010) Oral biofilms: a reservoir of transferable, bacterial, antimicrobial resistance. Expert Rev. Anti-Infect Ther 8:1441-1450

51. Silfrany RO, Caba RE, de Los S, Santos F, Hanning I (2013) Detection of quinolones in poultry meat obtained from retail centers in Santiago Province, the Dominican Republic. J Food Prot 76: 352-354

52. Silbergeld EK, Graham J, Price LB (2008) Industrial food animal production, antimicrobial resistance, and human health. Annu Rev Public Health 29:151-169

53. Preshaw PM, Hefti AF, Jepsen S, Etienne D, Walker C, Bradshaw MH (2004) Subantimicrobial dose doxycycline as adjunctive treatment for periodontitis. A review. J Clin Periodontol 31:697-707

54. Thaker M, Spanogiannopoulos P, Wright GD (2010) The tetracycline resistome. Cell Mol Life Sci 67:419-431

55. Ioannidis I, Sakellari D, Spala A, Arsenakis M, Konstantinidis A (2009) Prevalence of tetM, tetQ, nim and bla(TEM) genes in the oral cavities of Greek subjects: a pilot study. J Clin Periodontol 36:569574

56. Kim SM, Kim HC, Lee SW (2011) Characterization of antibiotic resistance determinants in oral biofilms. J Microbiol 49:595-602 